\title{
A Method for Measuring Operational and Financial Performance of a Production Value Stream
}

\author{
Tomasz Sobczyk ${ }^{1}$, Tomasz Koch ${ }^{1}$ \\ 1 Institute for Production Engineering and Automation, \\ Wroclaw University of Technology, \\ ul. Wybrzeze Wyspianskiego 27, 50-370 Wroclaw, Poland \\ WWW home page: http://www.pwr.wroc.pl/
}

\begin{abstract}
The paper explains the conceptual framework of so called costs, effects and resources map that is intended to support performance analyses of the production value stream. Its purpose is to enhance manufacturing decision taking processes by providing relevant information related to production flows. The tool consists of five modules: production system model (value stream map), cost module, financial statement and inventory valuation module, resources analyses module, and operational metrics module. The tool has been equipped with appropriate metrics that enable analyses of production system dynamics. In the last section of the paper example application of the tool in the production environment has been explained.
\end{abstract}

\section{Introduction}

Lean production (also known as the Toyota Production System) triggered a global transformation in virtually every industry over the last decade and became the foundation of dozens of books [1]. According to Womack, Jones and Ross, lean production is a means for rapidly developing world-class manufacturing skills without massive capital investments [2]. Many companies try to imitate the Toyota Way developing their production systems based on lean assumptions. However, numerous operational initiatives are often rejected as traditional cost accounting systems do not provide relevant and timely information to support them. Great amount of publicity has been generated by the writings of many authors criticizing current management accounting practices and their lack of relevance to today's business imperatives. Some authors advocate that many accounting textbooks teach the managers to put aside understanding the concrete particulars of how the business organizes work and focus exclusively on abstract quantitative generalizations about financial results [3]. According to Johnson managers too often manipulate processes

Please use the following format when citing this chapter:

Sobczyk, T. and Koch, T., 2008, in IFIP International Federation for Information Processing, Volume 257, Lean Business Systems and Beyond, Tomasz Koch, ed.; (Boston: Springer), pp. 151-163. 
to achieve accounting results, instead of monitoring well-run processes and occasionally checking accounting results [4]. Other authors suggest that cost cutting exercises are too often ritual activity which gives the appearance of something happening rather than the probably much needed but less comfortable rethink of some underlying causes of cost [5]. Some other argue that cost improvements not only come from reducing direct expenditures but also from properly managing indirect costs. According to Miller and, most production managers understand what drives direct labor and material costs but are much less aware of what drives overhead costs [6].

Value stream costing proposed by Maskell and Baggaley is one of the methods that can be successfully applied for measuring performance of a lean production system [7]. Although perfectly tailored for lean production organizations, it can be of little use by companies that are in an early stage of a lean journey. The authors articulate this by stressing the need for numerous "lean assumptions" that must be in place before the method can be effectively used [7, p. 140]. In the paper alternative method for measuring performance of a production system will be presented. The objective is to present a way of measuring system's performance regardless of the company's "lean maturity". The method is also intended to serve as a tool for monitoring current performance, estimation of gains envisioned by future state blueprints and individual improvement initiatives as well as assessment of value stream performance over time.

\section{Conceptual framework of the tool}

Production value stream's costs, effects and resources map (called hereafter value stream cost map) is a model used for measuring the performance of the selected manufacturing area modeled by means of the value stream map. The idea behind the model assumes the integration of a value stream map with a set of appropriate modules that aim at explicit description of the production system's state over time. The concept has been graphically presented in Figure 1.

The core of the model is given by the production value stream map (see 1 in Fig. 1). A Value Stream Mapping tool derives from Toyota's standard method for portraying material and information flows and was adapted by Rother and Shook into value stream maps [8]. According to Womack and Jones, the mapping process clearly reveals the potential for a major leap in performance if a relatively small number of flow and process improvements can be conducted and then sustained [9]. To measure the performance of any given value stream over time, four integrated modules have been proposed:

1. Cost module (or positioned cost pools module), in which each cost category is broken down into cost pools and any given cost pool is positioned along appropriate processes; the cost module enables assignment of costs to production entities (see 2 in Fig. 1);

2. Financial statement and inventory valuation module (see 3 in Fig. 1);

3. Resources analyses module (see 4 in Fig. 1);

4. Additional metrics module (see 5 in Fig. 1). 


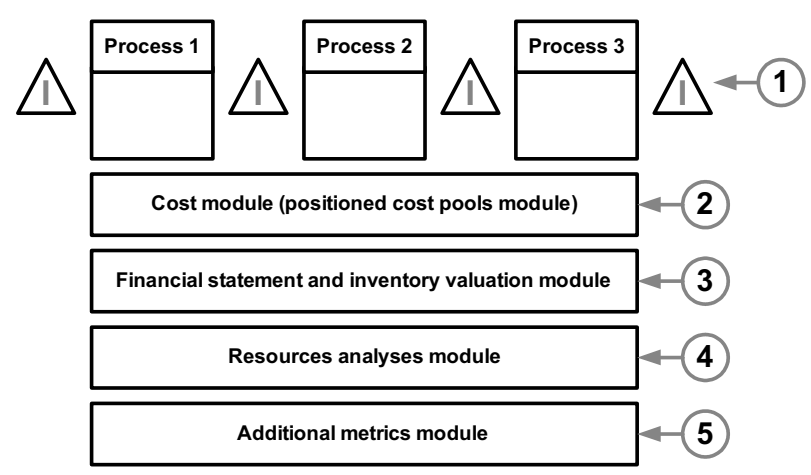

Fig. 1. Building blocks of the value stream cost map

Developed model represents a performance measurement platform that can be used for assessing any given production system in financial and operational terms. The model can support the analyses of:

1. State of the production system over time;

2. Financial consequences of changes presented on a value stream future state map along with establishing a set of necessary conditions required to implement operational ideas envisioned by a future state blueprint;

3. Individual improvement initiatives and investments (creation of financial scenarios based on different operational assumptions);

4. Value stream process costs and their root causes.

\subsection{Cost pools and cost objects. Assigning costs to cost objects.}

It has been assumed that in the model processes visualized by process boxes will form basic cost objects. Assignment of costs onto cost objects is a three-stage process that consists of the following steps:

1. Grouping cost into cost categories;

2. Braking cost categories into cost pools;

3. Assigning cost pools to a single process or group of processes.

It has been proposed that depending on the needs any cost category can be created. Cost categories must than be allocated to the processes (cost objects) using pre-defined cost pools. Three types of cost pools have been defined: single process cost pool, group of processes cost pool, and value stream cost pool. The example configuration of cost categories and their value stream assignment has been shown in Figure 2 . 


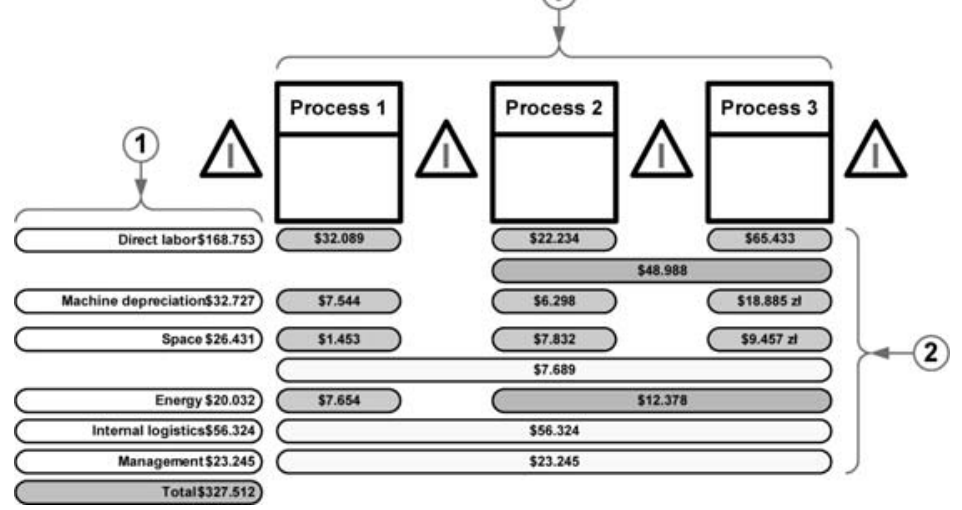

Fig. 2. Cost categories decomposed into cost pools. Assignment of cost pools into cost objects

Figure 2 shows six different cost categories (1). Costs within each category have been decomposed and assigned to the value stream processes (3) via cost pools (2). This enables for the following observations and conclusions:

1. How much costs is being used by the value stream and how much each category is worth;

2. How much costs is assigned to each process (or group of processes) in the value stream (for example it can be seen that process No. 1 requires as much as $\$ 32.098$ of the direct labor costs);

3. For creation of what cost is each of the value stream processes responsible.

This form of visualization is aimed at achieving production value stream cost identification and tracking. In addition, costs of shared resources can be visualized as value stream cost map is being created. This is true for both costs (resources) shared within sub-streams within any given value stream as well as costs (resources) shared by different value streams within the same company.

\subsubsection{Resources shared within different value streams}

Since a part of a value stream may be shared among different value streams within single production entity (what can not be seen on the value stream map), it is important to include this information on the value stream cost map. The way this information can be contained on the map has been visualized in Figure 3 .

Shaded cost pools on the cost map indicate that the processes share the resources (people, machines, space, etc.) with other value streams. In order to asses the level of sharing cost allocation must be performed. It is suggested that for this purpose single cost drivers are used or the calculations with use of activity-based costing method is performed [10]. It can be seen from Figure 3 that part of labor, machine and energy costs assigned to process No. 1 is shared with the value stream referred to as S2. On the other hand, value stream non-direct costs are the part of total overhead factory costs and are shared with two other value streams referred to as S2 and S3. 


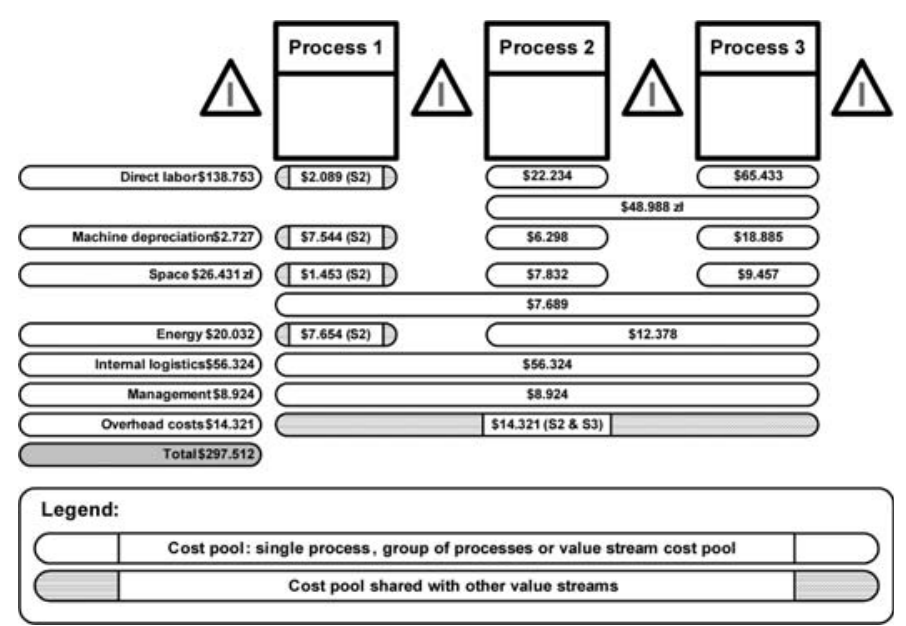

Fig. 3. Visualizing shared resources and their costs using value stream cost map

\subsubsection{Resources shared within different value stream sub-streams}

In the case a value stream consists of different sub-streams, value stream cost map shall contain cost information about each of them. The example of the cost map consisting of three parallel streams has been shown in Figure 4.

The figure presents example cost structure assigned to the main stream (A) and two sub-streams ( $\mathrm{B}$ and $\mathrm{C}$ ). The following are the general rules for the design of a cost map consisting of additional sub-streams (see Figure 4 for reference).

1. The main stream and sub-streams shall be identified (see respectively A, B and C on Figure 4);

2. All sub-streams ought to be located above main stream of the production value stream;

3. Processes belonging to sub-streams shall be assigned their own cost pools ( 1 and 2 respectively). It is suggested however, that the same cost categories as in the case of the main stream are used;

4. Cost pools of shared resources should be shaded (see also point 2.3);

5. Those cost pools that are shared both within main stream and sub-streams should be dotted. It is suggested that one writes down which processes or substream any given cost pool is shared with. For example:

a. Cost of energy is a shared cost of the main stream and all other substreams;

b. Labor cost is a cost shared between processes A3 and C2 (see 3 and 3' in Fig. 4);

6. Costs that are shared within the value stream and other company value streams should be plotted in vertical lines (see 7 in Fig. 4); 
7. One ought to calculate summary costs of each sub-stream (see 8, 9 and 10 in Figure 4) as well as total costs of the entire value stream (see 11 in Figure 4).

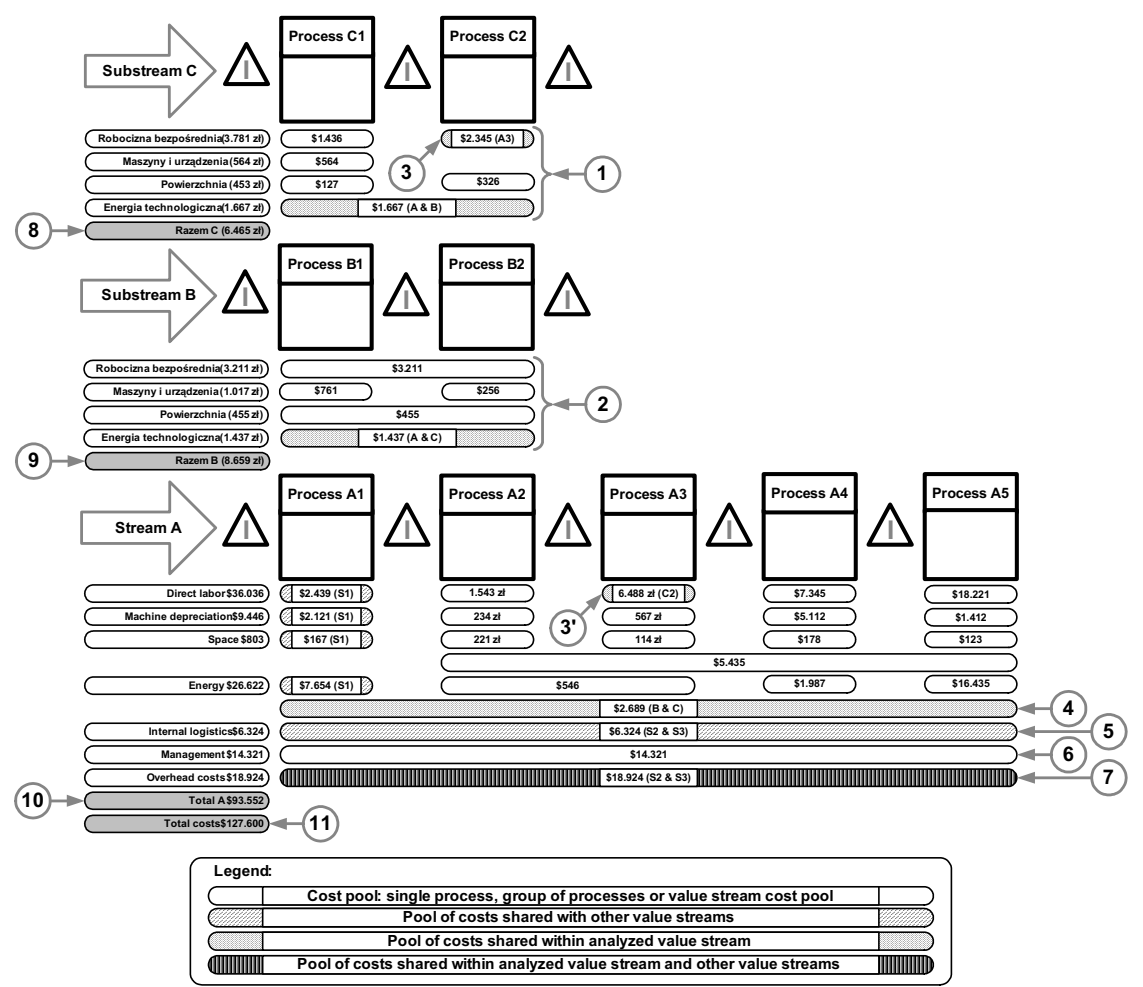

Fig. 4. Example value stream cost map consisting of the main value stream and two parallel sub-streams

\subsection{Financial statement and inventory valuation module}

Financial results are calculated using throughput costing methodology to prevent overproduction. This implies that all costs except from material costs are regarded period costs. What is more, in valuing the inventory only material costs are taken into consideration. Figure 5 presents the value stream cost map linked with financial statement and inventory valuation module.

Selected positions are related to:

1. Value of inventory at the end of the analyzed period (see 1, 2 and 3 in Fig. 5);

2. Income reported at the end of the analyzed period (see 4 in Fig. 5);

3. Cost of goods sold throughout the analyzed period (see 5 in Fig. 5);

4. Value stream costs incurred in the analyzed period (the sum of all cost pools);

5. Amount of revenue gained in the period. 


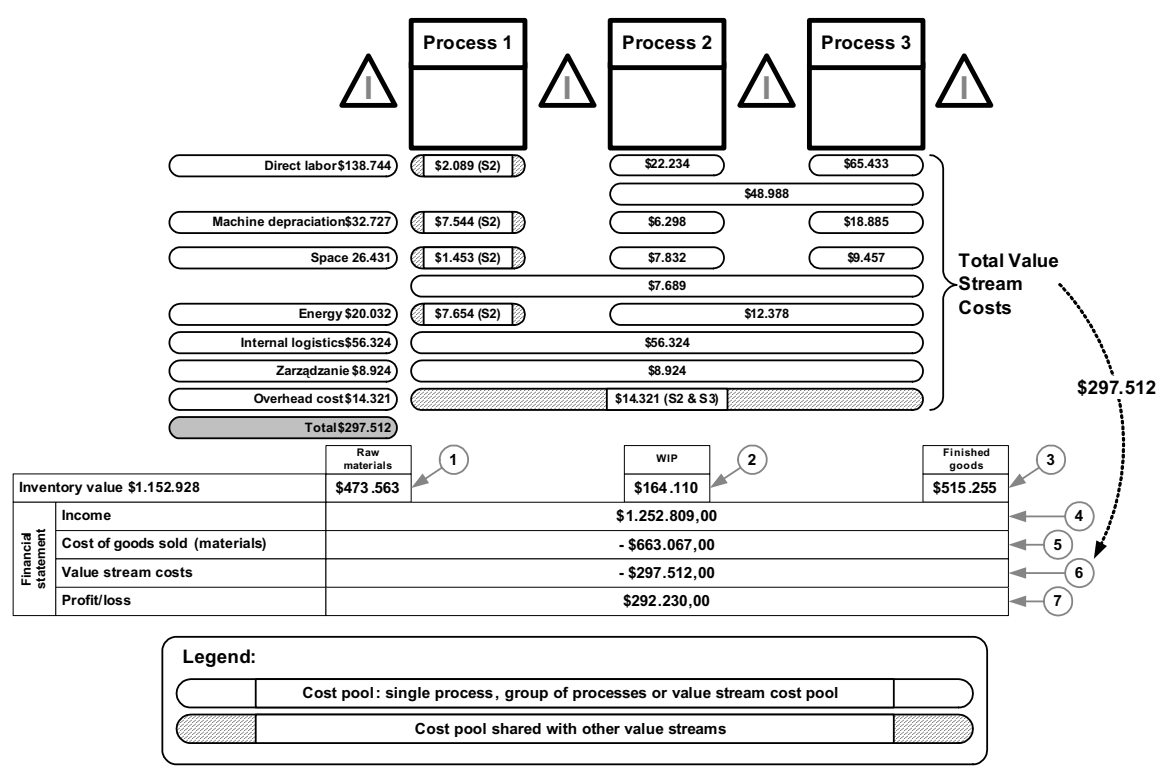

Fig. 5. Inventory valuation and profit calculation using value stream cost map

\subsection{System dynamics analyses}

The static nature of the value stream map and dynamic nature of the production system calls for measuring the state of the production entity over the time. The analyses of system's dynamics will be explained on the example of the analyses related to inventory value. This type of analyses is twofold and aims at establishing the following:

1. What is the value of inventory in the value stream and what had been the reasons behind the raise (or fall) of inventory value against previous reported period;

2. How current inventory relates to the overall, long-term trends.

Figure 6 presents the example of how the dynamics of inventory value can be tackled using value stream cost map.

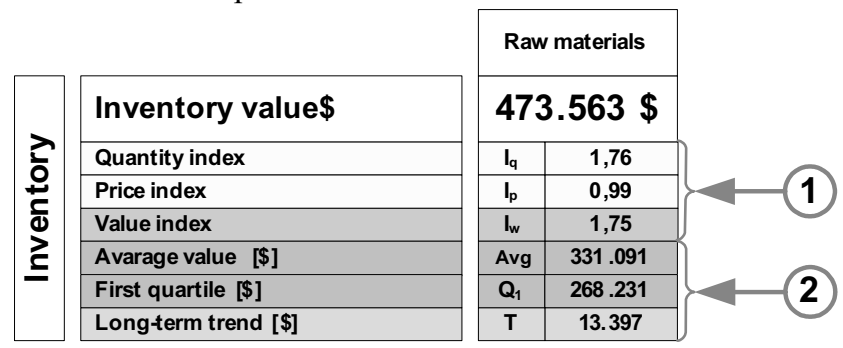

Fig. 6. Chosen parameters used for the analyses of system dynamics with use of value stream cost map 
Figure 6 presents raw materials section from the cost map presented in Figure 5. First set of indexes (1) explains the changes in the inventory value against last period. The second set of metrics shows the long-term inventory value trend. It can be deducted from the data seen in Figure 6 that $76 \%$ raise in volumes manufactured $\left(I_{q}=1,76\right)$ as well as $1 \%$ fall of prices reported in the last period $\left(I_{p}=0,99\right)$, resulted in $75 \%$ raise of inventory value $\left(I_{v}=1,75\right)$ as compared with previous reporting period. In addition, in $75 \%$ of cases the inventory residing in the system was worth more than $\$ 268.231\left(Q_{1}=\$ 268.231\right)$, and the company had to keep on average $\$ 331,091$ worth of inventory so far $(\mathrm{Avg}=\$ 331,091)$. What is more, average inventory value growth rate reached the level of $13.397 \$$ per period $(\mathrm{T}=\$ 13.397)$.

The same set of measures have been used for examining the dynamics of other parameters of the value stream cost map. Presented approach is intended to track the dynamics of the outcomes achieved through daily value stream management routines as well as changes to existing manufacturing practices.

\subsection{Resources analyses module}

Another important aspect of a production value stream performance measurement procedure is the way the actual use of resources is measured. At least two very important "lean" aspects should be taken into consideration:

1. Production equipment usage;

2. The use of human resources.

\subsubsection{Production equipment usage}

The method for measuring machinery usage has been graphically presented in Figure 7.

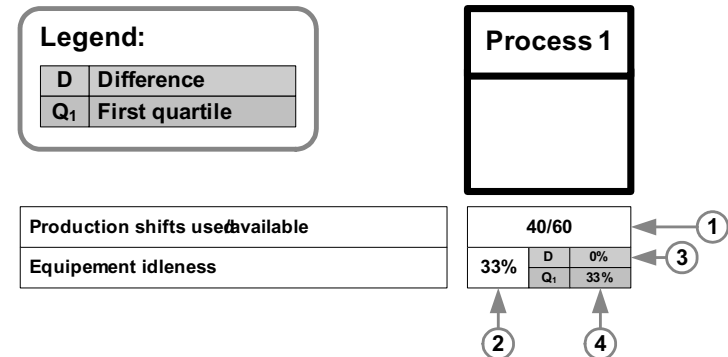

Fig. 7. Machinery usage in the last reported period - example analyses using value stream cost map

The data in Figure 7 suggests that the value stream carried out production on 40 out of 60 available production shifts within last reporting period (at the same time, 60 available production shifts equals maximum capacity of the value stream) (1). The data implies that machinery remained idle for $33 \%$ (2) of the time in the last period. Compared to the previous reporting period, no changes had been noticed in 
that matter (3). However $75 \%$ of cases, production equipment stayed non-productive for not less than $33 \%$ (4).

In addition to the usage of the machinery, it is important to consider the use of human resources as well as associated labor costs and its productivity.

\subsubsection{Human resources usage}

Given that human resources are active does not necessarily imply that they are productive. Hence, there is a need to distinguish between different types of human activities carried out and the amount of time they require. The basis for comparison is the time devoted to production which can be divided into categories shown in Figure 8 .

Each category that impacts the use of resources in a given process (1) has been assigned percentage of time out of total available time used by the process in the analyzed period (2). In addition, each category has been equipped with appropriate indexes similar to those presented on Figure 6 to measure the dynamics of changes as improvement initiatives take place (3).

Given the example from Figure 1 one can arrive at the following conclusions:

1. $40 \%$ of time the resources were used for actual production $8.3 \%$ of which was overproduction.

2. Even though production volume was higher than required, customer satisfaction reached only $95 \%$ (the value stream produced more than expected however not the part numbers that were needed) (4).

It important to realize that the time used for production was close to $40 \%$ what suggests that the rest of it was wasted (see relevant categories in Fig. 8). It also implies that one should search for causes of wasted human effort that is the effect of existing production practices.

If connected to the cost module, the tool enables the following:

1. Analyses of the cost of waste related to any activity within value stream;

2. Analyses of the potential gains due to waste elimination.

These two enablers will be explained in more detail in point 3.

\subsection{Additional metrics module}

Depending on the production type, metrics used by the company/corporation, or individual needs of the user, the cost map may be supplemented by additional set of operational and financial indexes. In addition, the dynamics of the parameters can be measured by means of proposed set of indexes explained in point 2.4. 


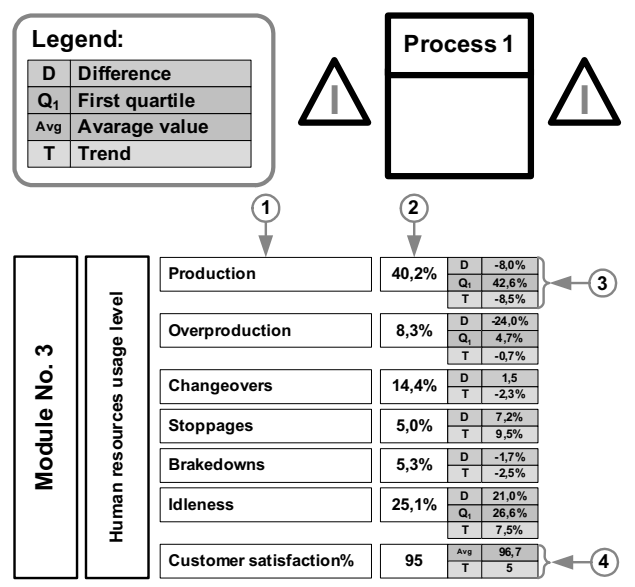

Fig. 8. Categories of activities performed by human resources employed in the production value stream - notation of the value stream cost map

\section{Application of the tool}

The application of the cost map will be explained on the example of the company manufacturing metal nets used in coal mines. The data was gathered on the basis of six-month project. Four complementary ways of use have been graphically presented in Figure 9.

As it can be seen in Figure 9, the model is based on the production current state value stream map (1). The tool can be used for the following analyses:

1. value stream current state operational and financial performance measurement (1);

2. monitoring operational and financial performance of the value stream over time (2);

3. operational and financial assessment of the future state blueprint;

4. operational and financial assessment of the individual improvement initiatives (both technical and organizational) (4).

The application of the latter issue will be explained in more detail in the following section of the paper. It has been assumed that the reference for the following analyses will be the cost map designed in May 2006.

\subsection{Operational and financial assessment of the individual improvement initiatives}

Modernization of the existing fabrication cell became the study with use of value stream cost map methodology. Improvement ideas became the subject to further assessment. Proposed changes were related to reduced cycle times and improved use of production resources. It had been assumed that additional investment $(\$ 1.320$ for 
fixtures and $\$ 5.000$ for employee training) would be required. Achieved results in form of the value stream cost map are presented in Figure 10.

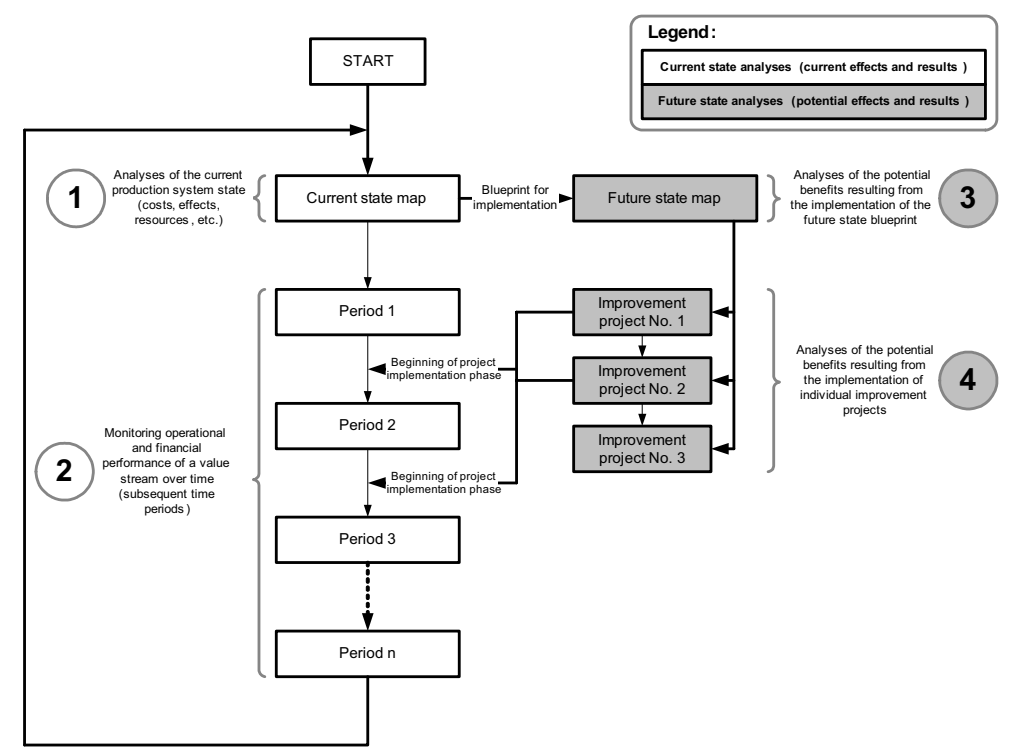

Fig. 9. Four complementary ways of using value stream cost map methodology

Expected changes to map's analytical positions have been colored. According to data in Figure 10 proposed organizational and technical changes lead to the following considerations:

1. The same production volume might be manufactured using half of the resources available (1); this in turn leads to $50 \%$ reduction in direct labor costs (2);

2. Increase in productive use (3) and at the same reduction in non-productive use of resources (4);

3. $10 \%$ reduction in value stream costs and $64 \%$ profitability increase (5);

Similarly to the future state financial considerations it is possible to propose many different scenarios based on different assumptions. What is more, the model can be used for assessing the impact of operational changes that may not have any influence on bottom-line results. In this case such a scenario may be rejected.

\section{Summary and conclusions}

The platform for measuring performance of a production value stream called value stream cost map has been presented. In the research work, value stream mapping method has been linked to the cost analyses module and integrated with: 1. financial statement and inventory valuation module (based on throughput costing methodology); 
2. resources analyses module;

3. operational metrics module.

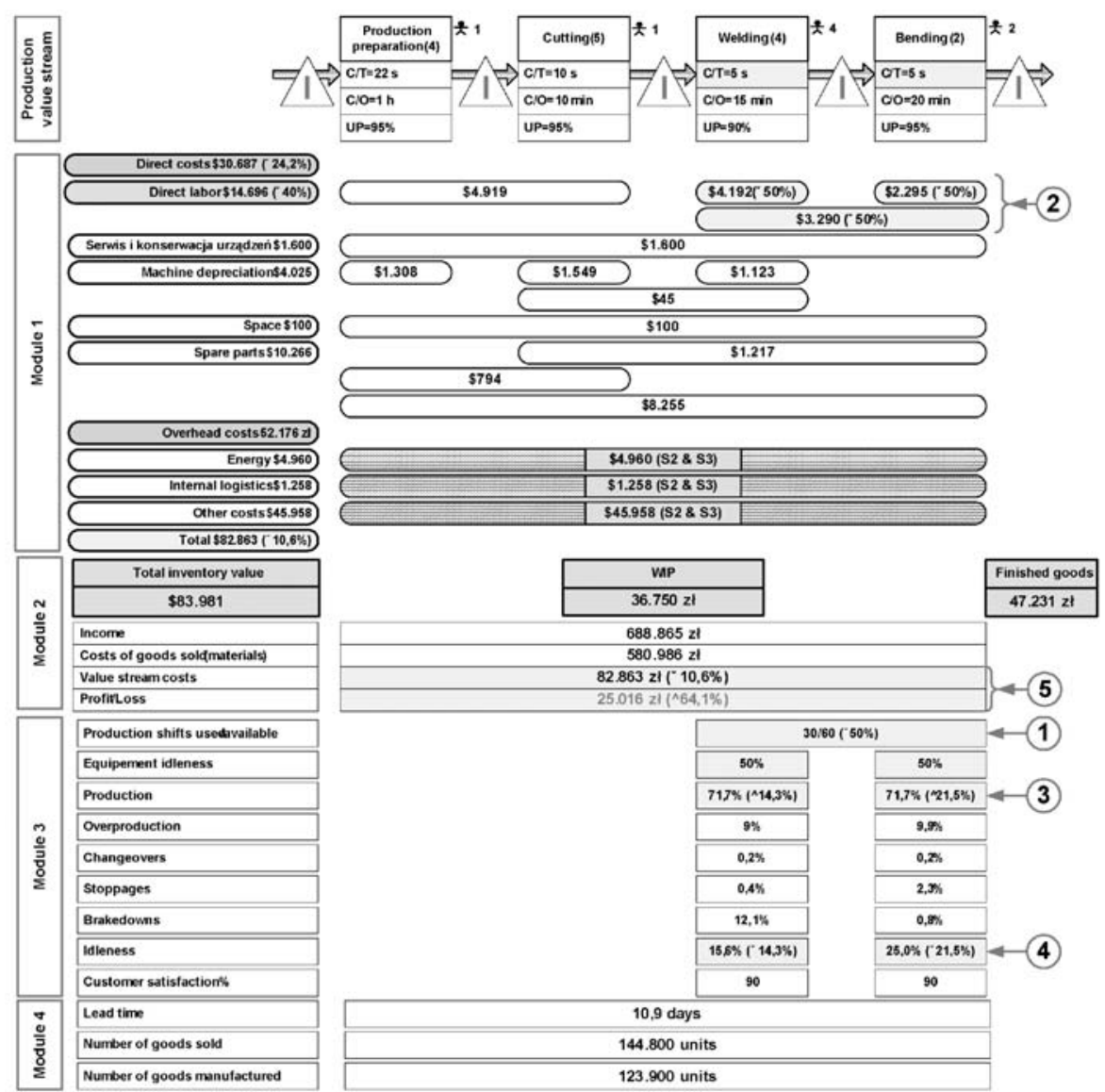

Fig. 10. Assessment and validation of the improvement project with use of value stream cost map

Graphical structure of the model supports analyses of the state of a production value stream with parallel focus on resources usage, costs, profits, value of inventory, and other important operational and financial parameters. The potential users of the model are manufacturing engineers and production managers who look for appropriate tool to support their strategic and daily operational decisions.

The model is an alternative solution for the existing performance measurement systems (particularly traditional cost accounting and management systems). It has been proved that it can be successfully applied by the production facility. The major distinction to value stream costing proposal is that the value stream cost map:

1. Does provide alternative method for measuring profitability and resources usage as well as the costs of individual processes and the entire value stream; 
2. Utilizes existing inventory valuation method based on throughput approach;

3. Does not require the resources (costs) to be dedicated process costs (it visualizes costs of shared resources);

4. Can be used by any company regardless of the maturity in Lean Manufacturing implementation;

5. Provides graphical representation of the value stream's operational and financial data - usually on one piece of paper;

6. Supports analyses of complex value streams with many fabrication sub-streams;

7. Enables the analyses of the dynamics of any given production value stream.

The method can be used by any company regardless of its size, country of origin or production profile as long as the production system can be modeled by means of the value stream map.

\section{References:}

1. Liker, J., K., The Toyota Way: 14 Management Principles from the World's Greatest Manufacturer, McGraw-Hill 2004.

2. Womack, J., P., Jones, D., T., Ross, D., The Machine That Changed the World. Who's ahead in the Global Auto Wars and why: Japan's Revolutionary Leap from Mass Production to Lean Production And What Industry Everywhere can Learn from, Simon \& Schuster Inc., p. 256.

3. Johnson, T.H.; Broms, A., Profit Beyond Measure : Extraordinary Results through Attention to Work and People, Free Press, November 2000, p. 58.

4. Johnson, T.H., 1992, Relevance Regained: From Top-Down Control to BottomUp Empowerment, Free Press, January 2002, p. 26.

5. Slack, N., 1992, The Manufacturing Advantage: Achieving Competitive Manufacturing Operations, Management Books 2000 (April 1992), p. 99.

6. Miller, J.G.; Vollmann, T.E., The Hidden Factory, Harvard Business Review, September-October 1985, p.143.

7. Maskell, B., H., Baggaley, B., Practical Lean Accounting. A Proven System for Measuring and Managing the Lean Enterprise, Productivity Press Inc. 2003.

8. Rother, M., Shook, J., Learning to See, Ver. 1.3, The Lean Enterprise Institute, 2003.

9. Womack, J.P.; Jones, D.T., Lean Thinking. Banish Waste and Create Wealth in Your Corporation, The Free Press 2003, p. 316.

10. Sobczyk, T., Koch, T., Cost Management Framework for a Value Stream, International Conference on Changeable, Agile, Reconfigurable and Virtual Production. 